\section{Materials Matter}

The message of the Materials Research Society has to be: "Materials matter!" As incoming MRS president, I see my most important role as a catalyst to get the word out about the vitality and necessity of materials discovery and materials technology. MRS defines materials research broadly, to include any activity that leads to materials innovation, application, and understanding, including the training and encouragement of future materials researchers. We even include the intrepid among us who are looking for technologies that provide alternatives and replacements for materials!

My aunts used to refer to the cloth for sewing trousers and draperies as "material," so I grew up thinking that material was always a textile. Not even just any textile, since for some reason, in my family, rugs and knitted sweaters were not referred to as "material." Certainly, neither were Play-Doh, Tupperware, glass, or aluminum foil. Of course, in those days, there was no such thing as silicon, as far as anyone gathered for a holiday meal in my grandmother's house would have known.

Even as I began to study chemistry and physics in high school and college, I can't say that I gave materials much thought. We don't typically think of atoms and molecules as materials, and we probably shouldn't. The sciences of physics and chemistry provide a thorough understanding of the nature of objects comprising up to a few hundred atoms or so. For many of us, chemistry and physics stopped at that point. In my graduate research group of synthetic chemists, we were encouraged to discard, rather than characterize, any matter (junk!) from a reaction mixture whose molecular weight reached the thousands.

Of course, I now appreciate that such "mystery matter" was where the chemical morphed into the material. Many fascinating substances exist at that critical point: proteins, clusters, dendrimers, micelles, exfoliated clays, catalyst particles, nanotubes, and so on. We can argue about

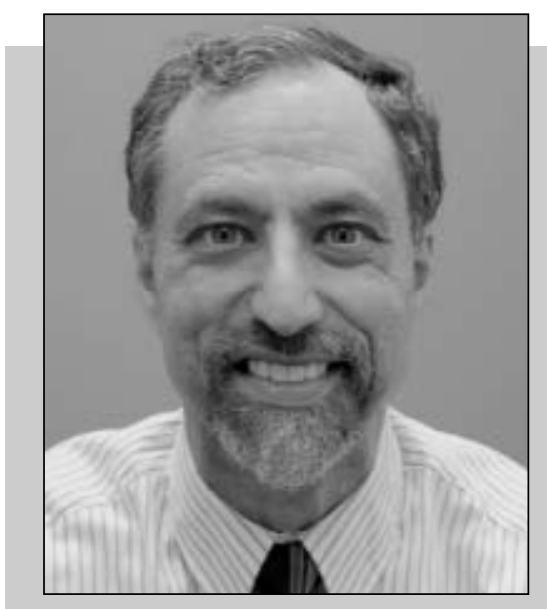

"Materials are the vehicles by which atoms, molecules, and even subatomic particles are manifest, not only as perceivable objects, but as technologies."

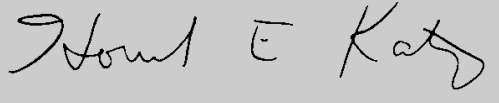

which of the items on this laundry list are materials, but I would propose that at least some of them are. The dimensions of materials extend from this list, out to the macroscopic (a wafer, a plate) and the "superscopic" (a highway). At some point, we would probably agree that some object might be defined more by an arrangement of parts, or by a function, and would therefore be thought of as being made of one or more materials, rather than being a material itself. Thus, a material can be deemed something that has at least one dimension larger than 10 or so nanometers, uniform in composition over some number of domains, and having that composition (rather than an architecture or function) as a main identifying feature. Smaller units of matter that resemble materials in some key way can also be considered to be in the realm of materials research, as can nanoscale features embedded in materials.

Materials are the vehicles by which atoms, molecules, and even subatomic particles are manifest, not only as perceivable objects, but as technologies. The nonstick properties of fluoropolymers, the strength of Kevlar, the luminescence of gallium nitride, and the multifunctionality of coronary stent materials are the basis for major businesses, some of them well established and others emerging. Investments are continually being made in future technologies that are based on materials such as zeolite catalysts, nanowires, metallic glasses, drug delivery membranes, and electroluminescent dye films. Furthermore, progress in the technologies of objects, such as replacement body parts and data storage media, are based substantially on the research and engineering of materials. These kinds of technologies are poised not only to underpin the economy, but as the MRS mission statement says, to "improve the quality of life."

So, let's say it again: "Materials matter!" Let's shout it from the rooftops, which we dream will someday be made of cheap and efficient solar cells. Let's rush to do this in our lightweight composite vehicles that squeeze every joule from their nonpolluting fuel, and that recapture the heat of braking with triboelectric brake pads. Most of all, let's celebrate the success of materials at our highly interdisciplinary and interactive meetings and in publications like this one, and make sure that the financial and technological decisionmakers (and the wider public who constitutes their constituency) get the message.

We in MRS are deservedly proud of our accomplishments and encourage everyone involved in materials-related activities, regardless of what "major" one might have designated in college, to identify with us, join the fun, add to the success, and make materials matter even more!

HOWARD E. KATZ 2004 MRS President

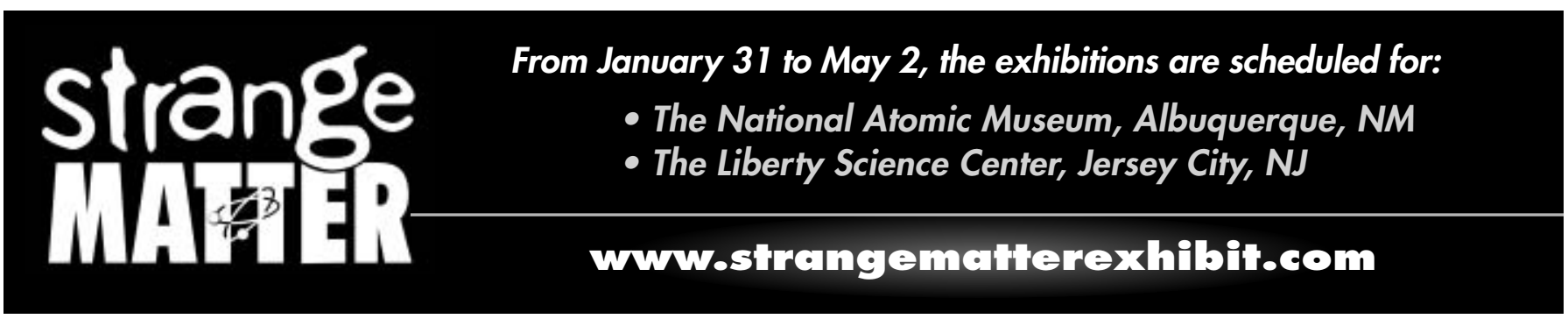

